\title{
Novel shifts in memory research and their impact on the legal process : introduction to the special issue on memory formation and suggestibility in the legal process
}

Citation for published version (APA):

Otgaar, H., Sauerland, M., \& Petrila, J. P. (2013). Novel shifts in memory research and their impact on the legal process : introduction to the special issue on memory formation and suggestibility in the legal process. Behavioral Sciences \& the Law, 31(5), 531-540. https://doi.org/10.1002/bsl.2095

Document status and date:

Published: 30/09/2013

DOI:

10.1002/bsl.2095

Document Version:

Publisher's PDF, also known as Version of record

\section{Document license:}

Taverne

\section{Please check the document version of this publication:}

- A submitted manuscript is the version of the article upon submission and before peer-review. There can be important differences between the submitted version and the official published version of record. People interested in the research are advised to contact the author for the final version of the publication, or visit the $\mathrm{DOI}$ to the publisher's website.

- The final author version and the galley proof are versions of the publication after peer review.

- The final published version features the final layout of the paper including the volume, issue and page numbers.

Link to publication

\footnotetext{
General rights rights.

- You may freely distribute the URL identifying the publication in the public portal. please follow below link for the End User Agreement:

www.umlib.nl/taverne-license

Take down policy

If you believe that this document breaches copyright please contact us at:

repository@maastrichtuniversity.nl

providing details and we will investigate your claim.
}

Copyright and moral rights for the publications made accessible in the public portal are retained by the authors and/or other copyright owners and it is a condition of accessing publications that users recognise and abide by the legal requirements associated with these

- Users may download and print one copy of any publication from the public portal for the purpose of private study or research.

- You may not further distribute the material or use it for any profit-making activity or commercial gain

If the publication is distributed under the terms of Article $25 \mathrm{fa}$ of the Dutch Copyright Act, indicated by the "Taverne" license above, 


\title{
Novel Shifts in Memory Research and their Impact on the Legal Process: Introduction to the Special Issue on Memory Formation and Suggestibility in the Legal Process
}

\author{
Henry Otgaar, Ph.D.*, ${ }^{\dagger}$, Melanie Sauerland, Ph.D. ${ }^{\dagger}$ and \\ John P. Petrila, J.D., LL.M. ${ }^{\ddagger}$
}

The functioning and frailties of memory are frequently at the centerpiece of much expert testimony about the reliability of eyewitness accounts. Although we have much knowledge about how false memories and suggestibility can affect testimonies, the contributions in this special issue show that when using a sound theoretical framework, novel directions in this field can surface. The papers in this issue can broadly be divided into contributions that are related to: (1) the exact determinants of false memory and suggestibility; (2) new paradigms in legal psychology; (3) positive consequences of memory illusions; and (4) developmental false memory research. Collectively, these contributions have the potential to provide novel shifts in memory research and push this field beyond its current boundaries. Copyright (C) 2013 John Wiley \& Sons, Ltd.

\section{NOVEL SHIFTS IN MEMORY RESEARCH AND THEIR IMPACT IN THE LEGAL PROCESS}

Decades of experimental and field research have shown that memory is fallible and that this recollective imperfection can exert disastrous consequences in the legal arena (e.g., Brainerd, Reyna, \& Ceci, 2008; Ceci \& Bruck, 1993; Wells, Memon, \& Penrod, 2006). Memory scholars understand that phenomena such as false memories and suggestibility are intertwined with basic cognitions. It is undeniable that these phenomena often occur in daily life and are part of a flexible system called memory. It is less evident, however, that new developments within the memory field have pointed to counterintuitive findings concerning a host of memory-related phenomena. Hence, the time is ripe to critically discuss existing memory studies in the context of new theoretical approaches that provide a fresh perspective in the area of memory and suggestibility. This special issue of Behavioral Sciences $\mathcal{E}$ the Law presents a series of papers that provide exciting new developments in the related areas of memory and suggestibility. Before briefly describing the new perspectives presented in this volume, it is worth providing a short background of the memory research that stimulated these new developments.

\footnotetext{
*Correspondence to: Henry Otgaar, Ph.D., Forensic Psychology section, Faculty of Psychology and Neuroscience, Maastricht University, Maastricht, the Netherlands. E-mail: henry.otgaar@maastrichtuniversity.nl

${ }^{\dagger}$ Maastricht University, the Netherlands

University of South Florida, FL
} 


\section{MEMORY IN THE LEGAL ARENA}

Discussions about the interplay of defects in memory in the legal arena date at least to the early 1900s. Alfred Binet (1900) was one of the first to argue that memory could be corrupted under suggestive interviewing conditions. Louis William Stern (bs12095-bib-00481904) and Guy Montrose Whipple (1909) were also among the first to publish scholarly work about the role of eyewitnesses in court. However, it was Hugo Münsterberg with his book On the Witness Stand (1908) who had a seminal influence with regard to the potential role psychology could play in addressing legal questions (see also Wells et al., 2006). For example, in that work, he discussed the tenuous relationship between eyewitness confidence and accuracy, effectively foreshadowing one of the signature issues in psychology and law.

Since the 1970s, primarily due to the work of Elizabeth Loftus on the fallibility of memory, there has been an expanding body of research on memory and eyewitness testimony (Loftus, 1979). Loftus clearly showed that memory can be adversely influenced by a wide variety of external factors. Her ideas laid the ground for experimentation into the use of misinformation to create false memories, and she showed that misinformation and suggestive questions can alter memory and create memories for non-experienced details or events (for a review, see Loftus, 2005). Issues regarding false memories have become the mainstay of much of the empirical work in memory (Brainerd et al., 2008).

Besides experimentation into eyewitness errors due to false memories of details and events, research began into the area of mistaken identifications of people, e.g., in identification procedures (Buckhout, 1974). One of the core themes of early research in this area was the distinction between system and estimator variables (Wells, 1978). The underlying idea was that some of the variables impacting eyewitness accuracy were under the potential control of the justice system (system variables), while other variables were not (estimator variables). For example, interviewing procedures are system variables because they can be controlled and adapted. On the other hand, the justice system cannot control the presence of a weapon during the crime. Rather, it can estimate what impact the presence of a weapon had on a witness's memory. Collectively, research into the fallibility of eyewitness memory and what factors exacerbate memory has become a main topic in the psychology and law area. Although this research has resulted in the development of critical knowledge with regard to the functioning of memory and the incorporation of that knowledge into interrogation and line-up administration guidelines for children and adults, ideas about how memory works are not fixed and are still subject to significant change.

\section{FALSE MEMORY AND SUGGESTIBILITY}

One of the areas that has been subject to a significant amount of experimental research concerns false memory and suggestibility. Because eyewitness statements are often the only piece of evidence in criminal court trials (Brainerd et al., 2008; Bruer \& Pozzulo, in press), it is imperative to understand how reliable these statements are. Research into adult false memory was mainly fueled by debate over the authenticity of recovered memories of sexual abuse (Lindsay \& Read, 1994), whereas research on the production of children's false memories was largely the result of child sexual abuse cases in which 
the reliability of children's accounts was contested (Garven, Wood, Malpass, \& Shaw, 1998; Goodman, 2006). Memory researchers have devised different ways to study false memories in the laboratory. Broadly speaking, the methods to evoke false memories in the lab involve either the use of suggestive pressure (i.e., the misinformation and implantation paradigm; Frenda, Nichols, \& Loftus, 2011) or reliance on endogenous processes (i.e., the Deese/Roediger-McDermott (DRM) paradigm; Deese, 1959; Roediger \& McDermott, 1995).

In the misinformation paradigm, participants can be presented with different types of materials (e.g., photographs) and then receive suggestive misleading information about what they had seen. During a final test session, many participants mistakenly include details from the misinformation into their memory reports (Loftus, 2005). A plethora of studies has been conducted using the misinformation paradigm and several key findings have been identified. For example, research has shown that misinformation and suggestibility effects are more pronounced in younger children than in older children and adults (e.g., Ceci \& Bruck, 1993; Otgaar, Candel, Smeets, \& Merckelbach, 2010), that true and false memories encompass similar patterns of brain activity (Stark, Okado, \& Loftus, 2010), and that warning participants about misinformation effects has only limited value (Eakin, Schreiber, \& Sergent-Marshall, 2003).

Even more powerful forms of suggestion have been used to induce false memories with the implantation paradigm. For example, some research has created false memories for entirely fictitious events (Loftus \& Pickrell, 1995; Porter, Yuille, \& Lehman, 1999) by confronting participants with fabricated stories about events that they ostensibly experienced in their childhood. In multiple interviews, participants are suggestively asked what they can remember about these fabricated events. These suggestive procedures have been shown to elicit implanted false memories in approximately 30-40\% of participants (Otgaar, Scoboria, \& Smeets, 2013; Wade, Garry, Read, \& Lindsay, 2002).

Studies using this paradigm have revealed that memories for plausible (e.g., hot air balloon ride; Pezdek, Finger, \& Hodge, 1997; Wade et al., 2002) and implausible events (e.g., abducted by a UFO; Otgaar, Candel, Merckelbach, \& Wade, 2009; Strange, Sutherland, Sharman, \& Garry, 2006), as well as positive and negative events (Otgaar, Candel, \& Merckelbach, 2008), can be implanted in both children and adults. Furthermore, script knowledge increases the formation of implanted false memories in children (Otgaar, Candel, Scoboria, \& Merckelbach, 2010; Otgaar, Smeets, \& Peters, 2012).

Besides using suggestive pressure, memory scholars have also resorted to the use of methods intended to induce spontaneous false memories; that is, false memories that arise without suggestive pressure and that are the result of endogenous processes, such as spreading activation (Brainerd et al., 2008). One of the most well-known and often-used methods herein is the DRM paradigm (Deese, 1959; Roediger \& McDermott, 1995). In this paradigm, participants are presented with word lists with associatively related words that are linked to a non-presented theme word, called the critical lure. Recall and recognition tests demonstrate that a significant proportion of participants misremember the critical lure. The DRM illusion is a robust phenomenon in adults, such that spontaneous false memories are difficult to inhibit and occur automatically (Howe, 2005; Kimball \& Bjork, 2002). Furthermore, it has been demonstrated that the DRM illusion is intimately associated with autobiographical memory, 
making it a promising method to examine both semantic and episodic memories (Gallo, 2010).

Researchers have also constructed several variants to conjure false memories (e.g., memory conformity paradigm). Most importantly, this paradigm-driven research has delivered significant insight into the frailties of memory. However, as in any area of scientific inquiry, the development of a robust body of knowledge does not mean a field is exhausted.

In this issue, we present a set of studies that provide novel perspectives into the area of false memory and suggestibility. Nearly all of the papers in this volume have used a theoretical framework as a starting point to derive and suggest resolutions to legal psychological questions. What is most interesting in reading these papers as a whole is that when certain specific theoretical predictions are made, novel and counterintuitive findings emerge regarding memory performance in the legal process. It is our hope and expectation that these contributions, individually and in the aggregate, will stimulate new research lines that will push this field a step further. The contributions made by the papers fall into four interdependent and somewhat overlapping domains: (1) mechanisms related to false memory and suggestibility; (2) new paradigms in legal psychology; (3) positive consequences of memory illusions; and (4) developmental false memory research. Each portends the need for new research paradigms in memory formation and suggestibility

\section{MECHANISMS RELATED TO FALSE MEMORY AND SUGGESTIBILITY}

One question that is at the heart of much false memory and suggestibility research has to do with which mechanisms underlie false memories and the susceptibility to suggestion. When misinformation and false memory research started, debate began as to whether misinformation truly impaired the original memory trace or whether effects like compliance might have an influence on the misinformation effect (Loftus, Schooler, \& Wagenaar, 1985; McCloskey \& Zaragoza, 1985; Tversky \& Tuchin, 1989). Discussions about the exact precursors of false memories are still lively, thereby showing that, to date, memory researchers are still attempting to provide a better grasp of the intricacies of memory illusions (e.g., Gallo, 2010; Otgaar, Verschuere, Meijer, \& van Oorsouw, 2012; Pezdek \& Lam, 2007; Wade et al., 2007). In the current issue, several contributions inquire into the possible mechanisms related to false memory and suggestibility.

Paz-Alonso, Goodman, and Ibabe, for example, report on a study about the role of social influences or compliance in the misinformation effect. Using a typical misinformation design with immediate and delayed testing sessions, they show that compliance predicted misinformation effects, especially on the delayed tests. More importantly, the authors used a negative valenced event in their study that dovetails nicely with recent research indicating that negative stimuli increase false memory formation (e.g., Gomes, Brainerd, \& Stein, 2013; Howe, Candel, Otgaar, Malone, \& Wimmer, 2010; Otgaar et al., 2008; Porter, Spencer, \& Birt, 2003).

In a provocative study, Aydin and Ceci suggest that the likelihood of accepting misinformation can be tied to differential patterns in our linguistic environment and 
culture. In two pilot studies, they reveal that Turkish- and English-speaking children differ in their degree of suggestibility depending on specific linguistic markers.

Studies about language and suggestibility can easily fall under the broader flag of individual differences in false memory formation and suggestibility. In that respect, Kaasa, Cauffman, Clarke-Stewart, and Loftus describe findings from a study that specifies the conditions when false sexual abuse allegations are likely to occur. They explain the role that suggestibility has on the occurrence of false sexual abuse allegations and describe the legal implications of their results.

One important question that lies dormant within the area of suggestibility is whether the recall of a witnessed event prior to later presented misinformation increases or decreases suggestibility. LaPaglia and Chan discuss a new memory phenomenon, called retrieval-enhanced suggestibility (RES), that implies that recalling an event before misinformation is presented amplifies suggestibility levels. They show why this effect counters the general view on the relation between earlier testing sessions and susceptibility to suggestive pressure. In their study, they present new evidence showing the circumstances under which RES will affect memory performance and when not.

To conclude, these four papers present the newest findings about which mechanisms might be involved in the production of false memories and suggestibility. Research in this domain remains relevant, as knowledge about this matter could help legal professionals and scholars to deal with eyewitness statements and index how reliable these statements are.

\section{NEW PARADIGMS IN LEGAL PSYCHOLOGY}

We have already emphasized that psychologists have constructed myriad methods to examine how false memories occur. Such methods are often called paradigms, resting, of course, on the concept of paradigm articulated by Kuhn (1970). According to Kuhn, a paradigm represents a shared view among researchers on how to solve and study a specific research question. When paradigms are replaced or broken, scientific progress can accumulate in unexpected new directions.

The methodologies or paradigms in such a shared view are important because they embrace the way that researchers attempt to grapple with a certain scientific question. In our case, the scientific endeavor relates to the phenomena of false memory and suggestibility. The invention of new methods/paradigms is therefore vital, as they have the potential to foster new ideas and stimulate scientific progress.

One important paradigm in the false memory and suggestibility field is the memory conformity paradigm (Wright, Memon, Skagerberg, \& Gabbert, 2009). In this paradigm, eyewitnesses discuss an event with each other and this discussion contains errors. It has been shown that eyewitnesses often incorporate errors of the other person into their memory reports and develop false memories of the event. Although this paradigm has been used frequently in both children and adults, Williamson, Weber, and Robertson provide a novel twist in the memory conformity literature. They investigated the idea that memory conformity is the result of perceptions of credibility and tested this by letting subjects participate in a discussion with people with high or low expertise in memory.

Sagana, Sauerland, and Merckelbach report on a study in which they used a paradigm that until recently has not been mainstream in the legal psychological field 
(Sauerland, Sagana, \& Otgaar, 2012). That is, in their study, they adapted a paradigm that elicits a recently discovered phenomenon called choice blindness (Johansson, Hall, Sikström, \& Olsson, 2005) and related it to the field of eyewitness identifications. In a typical choice blindness experiment, participants have to make several choices (e.g., choose the more attractive of two faces). After their decision, participants are presented with their choice and have to motivate their decision. The critical manipulation is that in a subset of trials, participants are presented with the alternative that they did not select. Intriguingly, a significant minority of manipulated trials is detected. Sagana and colleagues describe what happens when choice blindness enters the domain of eyewitness identification experiments.

A significant issue that concerns all memory-related phenomena that are crucial for the legal field is whether legal professionals (e.g., jurors, judges) are aware of the factors detrimental to eyewitness accuracy. This is a relevant research question, as these professionals have to weigh eyewitness statements, provide a final call on validity and reliability and reach a verdict. If such professionals do not possess the knowledge needed to make such weighty decisions, miscarriages of justice may readily occur. Houston, Hope, Memon, and Read show in two studies whether judges and a jury are indeed aware of general eyewitness memory issues and discuss whether training requirements are needed to increase knowledge in the legal field. This study shows that extending a paradigm (i.e., survey) to other relevant professionals in the legal community (judges, jury etc.) can lead to critical knowledge about how this community grapples with the functioning of memory.

To sum up, paradigm-driven research is necessary to accumulate knowledge in the legal psychology. The contributions in this issue offer novel approaches to increase the amount of paradigm-driven research, something that can assist in expanding our view about how memory works, how it can be contaminated, and how it can positively or negatively impact legal decision-making.

\section{POSITIVE CONSEQUENCES OF MEMORY ILLUSIONS}

Memory researchers often regard memory illusions to be intrinsically perilous. That is, when eyewitness reports are partly based on incorrect recollections, innocent suspects might be convicted and lose their liberty. Hence, it is not unexpected that researchers have gone to great lengths to demonstrate the circumstances under which false memories arise. As outlined earlier, many of the contributions in this issue add to this corpus of research and show the more negative side of false memories. However, researchers have also started to take a more functional approach on memory (e.g., Anderson \& Milson, 1989; Howe \& Otgaar, 2013; Klein, Cosmides, Tooby, \& Chance, 2002) that focuses on the evolution of memory. Much of this work was triggered by a recent research program (Nairne, Thompson, \& Pandeirada, 2007), demonstrating that when information is processed for its survival relevance, it enjoys superior memory performance. In this line of research, participants typically have to imagine a survival situation in that they are stranded in the grasslands of a foreign country without any water and food and in danger of predators. During this imagination task, participants have to rate a set of unrelated words for the relevance of the imagined situation. After a short distractor task, participants receive a surprise memory test. Research has consistently shown that this procedure amplifies memory performance above and beyond control 
conditions known to boost memory as well (e.g., intentional learning; Nairne, Pandeirada, \& Thompson, 2008). This supports the idea that our memory is especially engineered to encode, store, and retrieve information relevant to our survival.

Interestingly, not only does this survival processing lead to heightened true memory performance, but it also increases the production of false memories in both children and adults (e.g., Howe \& Derbish, 2010; Otgaar \& Smeets, 2010). The fact that false memories are also increased under survival processing implies that false memories can be adaptive, too, and could thus be advantageous. Howe and colleagues (e.g., Howe, 2011; Howe, Garner, Charlesworth, \& Knott, 2011) were the first to take this counterintuitive idea seriously. They showed that having false memories aided in the solution of complex problem-solving tasks. In this issue, Howe, Garner, and Patel present the latest results regarding the positive consequences of memory illusions.

The research that Howe and colleagues present is highly related to recent research focusing on the adaptive value of memory (Otgaar \& Howe, in press). Such studies are innovative because they look at both ultimate (i.e., why did memory evolve?) and proximate (i.e., what mechanisms underlie memory performance?) explanations of memory. Even more, studies such as those of Howe and colleagues fall nicely within a recent field of psychology called evolutionary legal psychology, which involves the manifestation of evolved psychological phenomena relevant for legal situations (Otgaar \& Howe, in press). This field attempts to deal with legal psychological questions from an evolutionary stance (e.g., what is repression and why should it exist?). All in all, this field shows that in addition to focusing on the "dark" side of false memories, it is imperative to recognize that false memories can be adaptive and can be beneficial as well.

\section{DEVELOPMENTAL FALSE MEMORY RESEARCH}

A plethora of research has demonstrated that children are more vulnerable to false memories and more easily persuaded by suggestive questions than adults (e.g., Ceci \& Bruck, 1993). This developmental pattern has been the cornerstone of much expert testimony regarding child witnesses and victims in legal proceedings. Accordingly, this assumption is often held among legal professionals and has led to the assumption that memory distortions are more likely to transpire in children than in adults and that, hence, interrogation sessions should be designed to maximize the reporting of true information and minimize the recall of errant information.

That this developmental pattern can be reversed is a finding that has recently attracted much scientific focus. This counterintuitive pattern is also called developmental reversal and refers to the finding that, under certain circumstances, adults and not children are more likely to form false memories (Brainerd et al., 2008). This indicates that the default assumption about false memory development (i.e., age-related decrease in false memory) is often untenable and could lead to faulty legal decisions.

Brainerd et al. (2008) were among the first to specify the theoretical conditions that would lead to a developmental reversal. They explained that false memories increase with age if false memories rely on the retrieval of gist traces (i.e., retrieving the underlying meaning of experiences). As mentioned earlier, a common task to induce false memories that preserve the gist of experiences is the DRM paradigm.

In this issue, Otgaar, Howe, Peters, Sauerland, and Raymaekers present new evidence showing what happens when developmental trends of different types of 
spontaneous false memories are compared and what the legal implications are of this comparison. They show that when using a sound theoretical framework, it can be predicted when standard developmental trends in false memories can be reversed. Work in this area remains important because the question of whether children or adults are the most vulnerable witnesses in terms of false memory propensity still arises frequently in legal cases (Brainerd, in press; Ceci \& Bruck, 1993).

\section{FINAL COMMENTS: THEORY AND PRACTICE}

There is no doubt that research in the area of false memory and suggestibility has delivered vital knowledge about the general functioning of memory. Even more, it has resulted in the creation of empirically based guidelines about how to deal with practical issues that appear in the legal arena (e.g., how should children and adults be interrogated?). In the current issue, we have assembled a set of contributions that present the cutting-edge research into the false memory and suggestibility field, presented by many of the key researchers in this field who provide their latest findings and relate these findings to the legal process.

What links these contributions is that they have the potential to shift the false memory and suggestibility field in new directions. More precisely, the contributions in this special issue are likely to stimulate new ideas related to mechanisms, paradigms, consequences, and developmental trends of false memory. To give a few concrete examples, the work reported in this issue about different precursors of false memory could guide legal professionals to be more cognizant of the diverse set of circumstances leading to false memories. Furthermore, the finding that false memories are not inherently negative, but are part of a flexible memory system could help debunk myths of memory (e.g., memory works as a video recorder) that often appear in the legal arena. Related to this, new work in the developmental false memory field is also likely to show that certain assumptions about false memory development (e.g., false memories decrease with age) are untenable.

In addition, what these studies have in common is that they have attempted to solve practical questions using a sound theoretical framework. That is, some authors identified certain issues in the legal arena and sought relevant theories that might help them to solve these issues. Others began from a theoretical framework and used this framework to derive predictions that could lead to novel ideas regarding false memory and suggestibility. We believe that such a combined theory/practice approach can only lead to new insights about memory and their impact on the legal process. In the end, solving important practical issues will only occur if the resolutions rest on sound theory.

\section{ACKNOWLEDGEMENTS}

This paper has been supported by a grant from the Edmund Hustinx Foundation and by a grant from the Netherlands Organization for Scientific Research (NWO 415-12-003) to H.O. 


\section{REFERENCES}

Anderson, J. R., \& Milson, R. (1989). Human memory: An adaptive perspective. Psychological Review, 96, 703-719.

Binet, A. (1900). La Suggestibilité. Paris: Schleicher Frères.

Brainerd, C. J. (in press). Developmental reversals in false memory: A new look at the reliability of children's evidence. Current Directions in Psychological Science.

Brainerd, C. J., Reyna, V. F., \& Ceci, S. J. (2008). Developmental reversals in false memory: A review of data and theory. Psychological Bulletin, 134, 343-382.

Bruer, K., \& Pozzulo, J. D. (in press). Influence of eyewitness age and recall error on mock juror decisionmaking. Legal and Criminological Psychology.

Buckhout, R. (1974). Eyewitness testimony. Scientific American, 231, 23-31.

Ceci, S. J., \& Bruck, M. (1993). Suggestibility of the child witness: A historical review and synthesis. Psychological Bulletin, 113, 403-439.

Deese, J. (1959). On the prediction of occurrence of particular verbal intrusions in immediate recall. fournal of Experimental Psychology, 58, 17-22.

Eakin, D. K., Schreiber, T. A., \& Sergent-Marshall, S. (2003). Misinformation effects in eyewitness memory: The presence and absence of memory impairment as a function of warning and misinformation accessibility. Fournal of Experimental Psychology: Learning, Memory, and Cognition, 29, 813-825.

Frenda, S. J., Nichols, R. M., \& Loftus, E. F. (2011). Current issues and advances in misinformation research. Current Directions in Psychological Science, 20, 20-23.

Gallo, D. A. (2010). False memories and fantastic beliefs: 15 years of the DRM illusion. Memory E Cognition, $38,833-848$.

Garven, S., Wood, J., Malpass, R., \& Shaw, J., III. (1998). More than suggestion: The effect of interviewing techniques from the McMartin Preschool case. Fournal of Applied Psychology, 83, 347-359.

Gomes, C. F. A., Brainerd, C. J., \& Stein, L. M. (2013). The effects of emotional valence and arousal on recollective and nonrecollective recall. Fournal of Experimental Psychology: Learning, Memory, and Cognition, 39, 663-677.

Goodman, G. S. (2006). Children's eyewitness memory: A modern history and contemporary commentary. fournal of Social Issues, 62, 811-832.

Howe, M. L. (2005). Children (but not adults) can inhibit false memories. Psychological Science, 16, $927-931$.

Howe, M. L. (2011). The adaptive nature of memory and its illusions. Current Directions in Psychological Science, 20, 312-315.

Howe, M. L., \& Derbish, M. H. (2010). On the susceptibility of adaptive memory to false memory illusions. Cognition, 115, 252-267.

Howe, M. L., \& Otgaar, H. (2013). Proximate mechanisms and the development of adaptive memory. Current Directions in Psychological Science, 22, 16-22.

Howe, M. L., Garner, S. R., Charlesworth, M., \& Knott, L. M. (2011). A brighter side to memory illusions: False memories prime children's and adults' insight-based problem solving. Fournal of Experimental Child Psychology, 108, 383-393.

Howe, M. L., Candel, I., Otgaar, H., Malone, C., \& Wimmer, M. C. (2010). The role of valence in the development of immediate and long-term false memory illusions. Memory, 18, 58-75.

Johansson, P., Hall, L., Sikström, S., \& Olsson, A. (2005). Failure to detect mismatches between intention and outcome in a simple decision task. Science, 310, 116-119.

Kimball, D. R., \& Bjork, R. A. (2002). The influence of intentional and unintentional forgetting on false memories. Fournal of Experimental Psychology: General, 131, 116-130.

Klein, S., Cosmides, L., Tooby, J., \& Chance, S. (2002). Decisions and the evolution of memory: Multiple systems, multiple functions. Psychological Review, 109, 306-329.

Kuhn T. S. (1970). The structure of scientific revolutions. Chicago: Chicago University Press.

Lindsay, D. S., \& Read, J. D. (1994). Psychotherapy and memories of childhood sexual abuse: A cognitive perspective. Applied Cognitive Psychology, 8, 281-338.

Loftus, E. F. (1979). The malleability of human memory. American Scientist, 67, 312-320.

Loftus, E. F. (2005). Planting misinformation in the human mind: A 30-year investigation of the malleability of memory. Learning $\mathcal{E}$ Memory, 12, 361-366.

Loftus, E. F., \& Pickrell, J. E. (1995). The formation of false memories. Psychiatric Annals, 25, 720-725.

Loftus, E. F., Schooler, J. W., \& Wagenaar, W. A. (1985). The fate of memory: Comment on McCloskey and Zaragoza. Fournal of Experimental Psychology: General, 114, 375-380.

McCloskey, M., \& Zaragoza, M. (1985). Misleading postevent information and memory for events: Arguments and evidence against memory impairment hypotheses. Fournal of Experimental Psychology: General, 114, 1-16.

Münsterberg, H. (1908). On the witness stand. New York: Doubleday, Page.

Nairne, J. S., Pandeirada, J. N. S., \& Thompson, S. R. (2008). Adaptive memory: The comparative value of survival processing. Psychological Science, 19, 176-180. 
Nairne, J. S., Thompson, S. R., \& Pandeirada, J. N. S. (2007). Adaptive memory: Survival processing enhances retention. Journal of Experimental Psychology: Learning, Memory, E Cognition, 33, 263-273.

Otgaar, H., Candel, I., Scoboria, A., \& Merckelbach, H. (2010). Script knowledge enhances the development of children's false memories. Acta Psychologica, 133, 57-63.

Otgaar, H., Candel, I., Smeets, T., \& Merckelbach, H. (2010). "You didn't take Lucy's skirt off”: The effect of misleading information on omissions and commissions in children's memory reports. Legal and Criminological Psychology, 15, 229-241.

Otgaar, H., \& Howe, M. L. (in press). What kind of memory has evolution wrought? Memory.

Otgaar, H., \& Smeets, T. (2010). Adaptive memory: Survival processing increases both true and false memory in adults and children. Fournal of Experimental Psychology: Learning, Memory, and Cognition, 36, 1010-1016.

Otgaar, H., Smeets, T., \& Peters, M. (2012). Children's false memories and additional script knowledge. Applied Cognitive Psychology, 26, 709-715.

Otgaar, H., Verschuere, B., Meijer, E. H., \& van Oorsouw, K. (2012). The origin of children's implanted false memories: Memory traces or compliance. Acta Psychologica, 139, 397-403.

Otgaar, H., Candel, I., \& Merckelbach, H. (2008). Children's false memories: Easier to elicit for a negative than for a neutral event. Acta Psychologica, 128, 350-354.

Otgaar, H., Candel, I., Merckelbach, H., \& Wade, K. A. (2009). Abducted by a UFO: Prevalence information affects young children's false memories for an implausible event. Applied Cognitive Psychology, 23, 115-125.

Otgaar, H., Scoboria, A., \& Smeets, T. (2013). Experimentally evoking nonbelieved memories for childhood events. Fournal of Experimental Psychology: Learning, Memory, and Cognition, 39, 717-730.

Pezdek, K., \& Lam, S. (2007). What research paradigms have cognitive psychologists used to study "False memory", and what are the implications of these choices? Consciousness and Cognition, 16, 2-17.

Pezdek, K., Finger, K., \& Hodge, D. (1997). Planting false childhood memories: The role of event plausibility. Psychological Science, 8, 437-441.

Porter, S., Spencer, L., \& Birt, A. (2003). Blinded by emotion? Effect of the emotionality of a scene on susceptibility to false memories. Canadian fournal of Behavioural Sciences, 35, 165-175.

Porter, S., Yuille, J. C., \& Lehman, D. (1999). The nature of real, implanted, and fabricated memories for emotional childhood events: Implications for the recovered memory debate. Law and Human Behavior, 23, 517-538.

Roediger, H. L., \& McDermott, K. (1995). Creating false memories: Remembering words not presented in a list. Fournal of Experimental Psychology: Learning, Memory, and Cognition, 21, 803-814.

Sauerland, M., Sagana, A., \& Otgaar, H. (2012). Theoretical and legal issues related to choice blindness for voices. Legal and Criminological Psychology. Advance online publication. DOI: 10.1111/j.20448333.2012.02049.x

Stark, C. E. L., Okado, Y., \& Loftus, E. F. (2010). Imaging the reconstruction of true and false memories using sensory reactivation and the misinformation paradigms. Learning E Memory, 17, 485-488.

Stern, L. W. (1903-1906). Beiträge zur Psychologie der Aussage. 2 volumes. Leipzig: Barth.

Strange, D., Sutherland, R., Sharman, S. J., \& Garry, M. (2006). Event plausibility does not affect children's false memories. Memory, 14, 937-951.

Tversky, B., \& Tuchin, M. (1989). A reconciliation of the evidence on eyewitness testimony: Comments on McCloskey and Zaragoza (1985). Fournal of Experimental Psychology: General, 118, 86-91.

Wade, K. A., Garry, M., Read, J. D., \& Lindsay, D. S. (2002). A picture is worth a thousand lies: Using false photographs to create false childhood memories. Psychonomic Bulletin E Review, 9, 597-603.

Wade, K., Sharman, S., Garry, M., Memon, A., Mazzoni, G., Merckelbach, H., \& Loftus, E. (2007). False claims about false memory research. Consciousness and Cognition, 16, 18-28.

Wells, G. L. (1978). Applied eyewitness testimony research: System variables and estimator variables. fournal of Personality and Social Psychology, 36, 1546-1557.

Wells, G. L., Memon, A., \& Penrod, S. D. (2006). Eyewitness evidence: Improving its probative value. Psychological Science in the Public Interest, 7, 45-75.

Whipple, G. M. (1909). The observer as reporter a survey of the 'psychology of testimony'. Psychological Bulletin, 6, 153-170.

Wright, D. B., Memon, A., Skagerberg, E. M., \& Gabbert, F. (2009). When eyewitnesses talk. Current Directions in Psychological Science, 18, 174-178. 